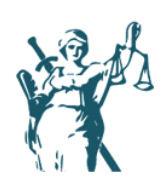

JUSTICIA

ISSN impreso 0124-7441

\title{
Aproximación a una Conceptualización de la Supremacía Constitucional a partir de la Jurisprudencia de la Corte Suprema de los EE. UU
}

\section{Approach to a Conceptualization of Constitutional Supremacy from the Jurisprudence of the Supreme Court of the USA. UU}

\author{
Héctor Mario Sulbaran Álvarez \\ Universidad de la Costa, Colombia \\ hsulbara1@gmail.com
}

Recibido: 18 de mayo de 2018 / Aceptado: 14 de septiembre de 2018

https://doi.org/10.17081/just.24.35.3396

\begin{abstract}
Resumen
El propósito del presente artículo es analizar la irrupción del neoconstitucionalismo, buscando definir un postulado ínsito en este: el principio de supremacía constitucional a partir de la jurisprudencia del máximo tribunal estadounidense, así como en simultanea se examina el fundamento jurídico-político del activismo judicial propio del referenciado paradigma. Se enmarca el tópico dentro de sus fronteras originarias: el derecho anglosajón, al mismo tiempo que se relaciona tangencialmente con el ordenamiento normativo colombiano en gracia a su tácito impacto en su estructura, máxime en su sistema de fuentes al tornarse como tendencia sucesora del fenómeno tradicional positivista. Se empleó como método la revisión documental del estado del arte a través de la búsqueda selectiva en bases de datos y el estudio de la literatura tratante de la temática, información procesada a través de fichas de revisión analítica (FRA), fichas bibliográficas y de lectura, así como de análisis jurisprudenciales estandarizados. Se conceptúa el principio de supremacía constitucional desde las principales doctrinas, previamente identificadas, suscitadas en el sistema administrativo federal estadounidense, concretamente del desarrollo del quehacer de la administración de justicia: las nociones del principio de supremacía constitucional en estricto sentido, la libertad de expresión y la hegemonía de raza, como constantes en el devenir de la Corte Suprema Estadounidense. Por último, se sienta una postura frente al sustrato posibilitador de la practica judicial como contenedor de los otros brazos del Estado y su auto-atribución para el ejercicio de las políticas públicas con fundamento en la supremacía constitucional.
\end{abstract}

Palabras clave: Supremacía constitucional, Scotus, Libertad de expresión, Hegemonía de raza, Activismo Judicial.

\section{Abstract}

The purpose of this article is to analyze the irruption of neoconstitutionalism, seeking to define an underlying postulate in this: the principle of constitutional supremacy from the jurisprudence of the US Supreme Court, as well as simultaneously examine the legal-political basis of the judicial activism itself of the referenced paradigm. The topic is framed within its original borders: The Anglo-Saxon right, while 


\section{Héctor MarioSulbaran Álvarez}

tangentially related to the Colombian normative order thanks to its tacit impact on its structure, especially in its system of sources to become the successor trend of the traditional phenomenon positivist.

The documentary review of the state of the art was used as a method through the selective search in databases and the study of the literature dealing with the subject, information processed through analytical review sheets (FRA), bibliographic and reading cards, as well as standardized jurisprudential analyzes. The principle of constitutional supremacy is conceptualized from the main doctrines previously identified, raised in the US federal administrative system, specifically the development of the task of the administration of justice: the notions of the principle of constitutional supremacy in a strict sense, freedom of expression and the hegemony of race, as constants in the evolution of the Supreme Court of the United States. Finally, a position is set against the enabling substrate of judicial practice as a container for the other arms of the State and its self-attribution for the exercise of public policies based on constitutional supremacy.

Keywords: Constitutional supremacy, Scotus, Freedom of expression, Race hegemony, Judicial activism.

\section{Como citar:}

Sulbaran Álvarez, H. (2019). Aproximación a una Conceptualización de la Supremacía Constitucional a partir de la Jurisprudencia de la Corte Suprema de los EE. UU. Justicia, 24(35). 104-120. https://doi.org/10.17081/just.24.35.3396 


\section{INTRODUCCIÓN}

Discurriendo sobre aspectos varios concernientes al paradigma neoconstitucional, máxime críticas a su composición como corriente de la dogmática jurídica, el profesor Aldunate (2009), trae a colación a modo de remembranza una interpelación alegada a su postura en un conversatorio académico pretérito ocurrido en la casa de estudios Diego Portales en Santiago de Chile, consistente en la exigencia de una elección de enfoque a favor o en contra de la citada visión del sistema normativo; otorgando como contestación su imposibilidad decisoria consecuente con la laya heterogénea, a su juicio, de esta forma de caracteres de la cultura jurídica contemporánea, al decir de Sanchís (2009), admitiendo en simultánea a la respuesta concedida, que lo único válidamente atribuible a esta era la confirmación de su existencia.

Lo anterior para advertir que al margen de las discusiones dialécticas-pragmáticas relativas a la conveniencia, imprudencia o lo nocivo de la regencia de esta tendencia sucesora del fenómeno positivista de la filosofía jurídica moderna, parafraseando a Comanducci, Ahumada \& Gonzalez (2009), su imperio es , sin lugar a dudas, incontrovertible hogaño, ergo se configura una labor un tanto problemática definir en términos originales algo que resulta tan común en la actualidad como lo es el principio de supremacía constitucional, intrínseco al auge de esta ideología adoptada plenamente en el ordenamiento nacional desde que se profirió la providencia C-836 de $2001^{1}$. De ello que abordar dicho tema en sus nociones primigenias, implique un ejercicio no menor de desaprender parcialmente los saberes y conceptos adquiridos desde la academia como en el ejercicio profesional, de esta base estructural del Estado mismo como se enarbola hoy por hoy la jerarquía omnímoda del texto constitucional y las exegesis efectuadas de este por parte de su cuerpo colegiado competente.

Si bien es cierto que la labor trazada por estas líneas se ciñe sobre el principio de supremacía constitucional desde una contemplación jurisprudencial en el sistema anglosajón, el enunciado aprieto subsiste debido a la adopción de sus elementos esenciales en la estructura del ordenamiento jurídico local, que pese a ser de corte eminentemente continental, se ha descubierto influenciado por el primero de sobremanera en lo que incumbe al rol del juez y la valía vinculante de los pronunciamientos del tribunal constitucional ${ }^{2}$.

No obstante, se propenderá por dar una respuesta solvente a los interrogantes instaurados, a saber: ¿Qué es el principio de supremacía constitucional? y ¿Cómo la Corte Suprema de los Estados Unidos con fundamento en este ha implementado políticas públicas? Siendo tácita la circunscripción que para tal efecto ha de hacerse en corrientes teóricas específicas, principalmente en el activismo judicial, a la que un considerable sector de la doctrina especializada en la materia, endilga su génesis a la misma colegiatura en comento ${ }^{3}$; a la par de que será menesteroso indagar por fuera del marco territorial, conceptual e histórico sugerido en aras de un abordaje integral del principio de hegemonía constitucional.

\subsection{Germen y Esencia del Principio de Supremacía Constitucional}

I Se imputa a esta la apertura y el reconacimiento formal del fenómeno neacanstitucional al orden jurídica, arragada a este can la misma expedición de la carta del Gl (Véase Art. 4 de la Canstitución), esta par traducirse en la definición del carácter vinculante del precedente judicial en todas las jurisdicciones sienda el culmen de la incorparación plena en el sistema de fuentes (Art. 230 de la Canst. Palítica) incoada desde la Sentencia. T- 123/95.

2 En el sentida de la incidencia jurídica del Cammon Law en el sistema colambiano, véase: Barrosa, L. (Julio-diciembre de 20IC). La Americanización del derecho constitucional y sus paradajas. Teoría y jurisprudencia constitucional en el mundo contemporáneo. ReDCE, 7(14), 365-426. / Alemán Peñaranda, I.M. (septiembre, 2009). La jurisdicción constitucional y la acción de tutela como control de constitucionalidad. Revista Justicia Juris, 6(II), 45-64.

3 En particular hacen referencia a la sentencia Brown v. Board of Education of Topeka (1954) 
En el ejercicio de búsqueda y revisión documental se hizo notoria la unanimidad consolidada entre los tratadistas relativa a acoger como el antecedente por antonomasia del paradigma neoconstitucional las expediciones de la Constitución de Italia en 1947 así como la ulterior Ley Fundamental de Bonn en Alemania durante $1949^{4}$ ambas fuertemente motivadas por el periodo de posguerra común a la Europa urgida por el restablecimiento del orden político y jurídico; empero la mencionada exploración permitió considerar con una exigencia mínima de correlación que el punto de partida genuino de este arquetipo de Estado del cual es derivativo el principio de supremacía constitucional, se sitúa realmente no en dichos sucesos históricos ni en las decisiones judiciales de la Corte Suprema de los Estados Unidos sujetos a estudio, sin implicar esta modesta apreciación personal el desconocimiento del valor icónico de tales hechos o de sentencias tan populares como la afamada Marbury $v$. Madison, ambos de inestimable rubro y tradición en el desarrollo del concepto neoconstitucionalista contemporáneo, aun así se prefiere ante estas el también celebre caso Bonham (1606) dirimido en forma inédita por el Tribunal del Common Pleas británico presidido por su Chief of Justice Sir. Edward Coke, del cual un sustrato factico carente de las connotaciones políticas de las que gozó posteriormente el fallo del Juez Marshall previamente enunciado en este acápite, le valió a su pretor para extractar de él, el gen epistemológico que a la postre se desarrolló en el principio de supremacía constitucional. Con fines de constatarlo, resulta útil traer a la palestra el siguiente comentario hallado:

[...] En varias oportunidades reaccionó (Sir. Edward Coke) contra la corona y el parlamento argumentando la existencia de un derecho fundamental que no podía ser desconocido. Para la época de Coke, el derecho estaba amenazado por la máxima expansión del poder real, lo que evidenciaba una gran debilidad en el sistema ingles por la falta de un mecanismo para proteger la esfera del derecho de intromisiones de la Corona. Por ello es de destacar la heroica labor adelantada por este jurista, porque gracias a él y a la actividad en general de los tribunales se hizo posible el predominio del derecho, de la [razón artificial], como la llamó, sobre los actos repugnantes, contrarios a la razón y al derecho común. (Velásquez, 1998: 2) Paréntesis fuera de texto.

Es dable colegir de lo incorporado luego, que la alusión a lo denominado derecho fundamental, pretendía constituirse como un muro de contención o impedimento eficaz para asegurar los límites al ejercicio del amplio poder monárquico, de tal manera que se apelara al derecho de gentes como soporte ideológico del mismo en virtud de la legitimidad concedida por la naturaleza consuetudinaria de este.

El segmento de la sentencia resolutoria del caso mencionado, que hace acreedor a este personaje de esos mayúsculos epítetos, es igualmente reseñado por la autora citada de esta forma:

Aparece en nuestros libros que en muchos casos el Common Law controla Acts del parlamento y que a veces los relega a la absoluta nulidad: porque cuando un Acts del parlamento se opone al derecho común y a la razón, o repugna o es de imposible aplicación, el Common Law lo controla y se impone sobre tal Acts, anulándolo. (Velásquez, 1998: 4)

Aunque circulando alrededor de este pasaje orbitan controversias históricas respecto a la conciencia del fallador al emitir su pronunciamiento y condicionar los productos de las deliberaciones legislativas a la observancia de lo que distinguió como derecho fundamental, o si

4 Compendian dicho consenso en sus obras autares cama: Juan Manuel Romero Martínez en "Marco Histórica, Filosófica y Teórico del Neoconstitucionalismo". De igual modo Eduardo Mata Méndez en "Tendencias Mexicanas del Constitucionalismo Maderno" Capitulo "Marco Histórico". 
de hecho lo realmente acaecido fue el remedio de una normativa contrapuesta en sí misma ${ }^{5}$, el mérito del dictum emerge indemne del debate por la lógica de la escasa probabilidad de provenir tan sesuda consideración del azar o la trivialidad de la aplicación rutinaria de las leyes consistente por aquella época en las simples tareas de subsunción.

Por otra parte, con posterioridad cercana a los dos siglos, en territorio estadounidense se sometía a consideración de las múltiples asambleas estatales la ratificación de la constitución federal, encontrando como promotores y defensores de su aprobación a los autores por ese entonces anónimos del acervo de ensayos que poco después se agruparían bajo el popular título de "El Federalista" (1788), obra que en su aparte dedicado a la organización y distribución del poder judicial enuncia en cuanto a sus competencias lo transcrito a continuación:

Las limitaciones [a la autoridad legislativa] sólo pueden mantenerse en la práctica a través de los tribunales de justicia, cuyo deber ha de ser el declarar nulos todos los actos contrarios al sentido evidente de la Constitución. Sin esto, todas las reservas que se hagan con respecto a determinados derechos o privilegios serán letra muerta. (Hamilton et al., 2015:474) Paréntesis fuera de texto.

Siendo concluyente de ello que la idea predecesora de Sir. Edward Coke encontró calado y evolución en las doctrinas americanas con la singular divergencia de lo que se consolidó en este como limitante y controlador del despliegue parlamentario fue en lugar del derecho natural, la rigidez inmanente de la constitución escrita. Se percata igualmente la influencia del magistrado inglés en los autores al sostener al tenor literal de aquel que los derechos subjetivos o reconocimientos legales otorgados sin medio idóneo para su guarda y validez, ostentan inutilidad inherente.

Dentro de la exposición de reflexiones, prosigue el ensayista relatando la naturaleza de la que se reviste la jurisdicción en el andamiaje institucional propio del Estado concebido en la carta política con el univoco propósito de justificar las atribuciones del poder judicial y neutralizar las alegaciones de lo que se podría llamar una imbricación de la esfera de los jueces en los campos de resorte del ramo legislativo, sobre esto expresó:

No hay proposición que se apoye sobre principios más claros que la que afirma que todo acto de una autoridad delegada, contrario a los términos del mandato con arreglo al cual se ejerce, es nulo. Por lo tanto, ningún acto legislativo contrario a la constitución puede ser válido. Negar esto equivaldría a afirmar que el mandatario es superior al mandante, que el servidor es más que su amo, que los representantes del pueblo son superiores al pueblo mismo y que los hombres que obran en virtud de determinados poderes pueden hacer no sólo los que estos no permiten, sino incluso lo que prohíben. (Hamilton et al., 2015: 474)

Con la argumentación anterior se propendía por darle grueso soporte racional a la limitación instaurada al margen de maniobra dispensado al legislativo por cuestiones capitalmente de censura democrática y tutela de la integridad requerida de los componentes básicos, especialmente en los que abarcan materia de derechos consagrados expresamente en la constitución. Continúa en el mismo sentido el autor discurriendo acerca del asiento del poder judicial en la estructura del Estado:

Los tribunales han sido concebidos como un cuerpo intermedio entre el pueblo y la legislatura, con la finalidad, entre otras varias, de mantener a esta última dentro de los límites asignados a su

5 Discusiones propulsadas principalmente par Harold J. Cook en: "Against Common Right and Reasan: The College of Physicians v. Dr. Thomas Banham". 
autoridad. La interpretación de las leyes es propia y peculiarmente de los tribunales. Una constitución es de hecho una ley fundamental y así debe ser considerada por los jueces. A ellos pertenece, por lo tanto, determinar su significado, así como el de cualquier ley que provenga del cuerpo legislativo. Y si ocurriere que entre las dos hay una discrepancia, debe preferirse, como es natural, aquella que posee fuerza obligatoria y validez superiores; en otras palabras, debe preferirse la constitución a la ley ordinaria, la intención del pueblo a la intención de sus mandatarios (Hamilton et al., 2015: 475).

Bajo esa tesitura, trascendió en un no calmado proceso evolutivo, la noción de la inferencia razonable según la cual al reconocer la categoría superior del texto constitucional es consecuente con ello la facultad de sus operadores de distinguir y excluir aquellas disposiciones normativas antónimas al espíritu fijado por el soberano a través de esta. El evento puntual que se instituyó en el nacimiento formal del examen de adecuación de las leyes frente a la constitución y la segregación ulterior de las que no superaran tal análisis, Judicial Review, se puede identificar en el siguiente fragmento de la previamente aludida sentencia Marbury v. Madison:

Está fuera de toda duda que o la constitución se impone a cualquier Ley que la contradiga o, por el contrario, el legislativo puede modificar la constitución a través de una Ley cualquiera. Entre estas dos opciones no hay término medio. O la constitución es un Derecho superior, principal, e inmodificable a través de mecanismos ordinarios o, por el contrario, se sitúa al mismo nivel que las leyes ordinarias, y como toda Ley es modificable cuando así lo disponga la voluntad del legislativo.

Si la primera parte de la alternativa fuese cierta, entonces una Ley contraria a la constitución no es Derecho. Si la cierta fuese la última parte las constituciones escritas no serían más que intentos absurdos del pueblo de limitar un poder que por naturaleza escaparía a todo limite.

Está claro que todos aquellos que dieron vida a la constitución escrita la han concebido como el Derecho fundamental y supremo de la nación y, consecuentemente, la regla que debe aplicarse es que toda Ley contraria a la constitución es nula.

Este principio es ínsito a una constitución escrita [...] (Gonzalez \& Beltran de Felipe, 2006:117)

Se desliga del aducido segmento, la incorporación implícita de una inspiración irrefutable al pensamiento de Hamilton por parte del Chief of Justice Juez John Marshall en lo tocante al papel del tribunal supremo como contrapeso al del desenvolvimiento parlamentario dentro del funcionamiento de la nación; tan así que no vacila en fijar como absoluto el gobierno de la constitución en la plenitud del sistema, convalidando su tendencia a la permanencia y lo excepcional de sus modificaciones.

Se originó entonces lo que hoy por hoy se denomina control abstracto de constitucionalidad, parangón que estudia la compatibilidad de los cuerpos normativos promulgados por los poderes democráticos respecto a los elementos constitutivos de la constitución como ley fundamental, esto es, sus valores, principios y reglas, ejercicio que finiquita con la emisión de un juicio de valor en sentido favorable que implica su incorporación o continuidad en el sistema jurídico, o por el contrario, en su desecho cuando estas no se aprecian armónicas a las disposiciones o esencia de la carta superior; Función que en términos Kelsenianos corresponde a la de un legislador negativo, con la salvedad de que dicho autor consideraba necesario la atribución de tal facultad a una corporación (magistratura especializada distinguida por su entera autonomía) cuyo objeto 
exclusivo fuera ese, en forma concentrada, y no la de un mero guardián de la constitución. (Trovao Do Rosario, 2015: 732-733)

Retomando esta tentativa de definición a partir de los tres ítems suscritos y concadenados, a criterio propio, en un devenir dependiente, el naciente por el antecesor, de la forma en que fueron expuestos, es tiempo entonces de proceder a conceptuar el principio de supremacía constitucional, del cual se puede decir, es el precepto recopilador de la garantía de un ordenamiento jurídico uniforme, irradiado en su extensión por las disposiciones máximas estipuladas en la carta superior, revestidas de carácter fundamental por emanar del poder político en su expresión esencial y protegidas en su integridad por el carácter vinculante de los fallos producidos con ocasión a su interpretación por el órgano del poder judicial competente.

Sin embargo, a las luces de la retórica es sencillo articular términos armoniosamente, sin decir que el conexo intento lo sea, pero ¿Que entraña realmente el principio de supremacía constitucional? para finalizar este aparte disipando tal pregunta, se opta por valerse de estas respuestas, la cual lo abrevia con referencia a la carta política así : "[...] todos los órganos del Estado deben someter su actuación a ella; que las normas infra-constitucionales son válidas en cuanto se conforman a ella; en que nadie en ninguna circunstancia puede arrogarse derechos o atribuciones que no estén amparados por ella" (Silva Irarrázaval, 2012:575).

\subsection{La Cuestión Racial en el Marco del Constitucionalismo Ejercitado por la Corte Suprema de los Estados Unidos}

Las distintas sociedades a lo largo del tiempo se han visto subsumidas en diferentes cosmovisiones, paradigmas sustentados por una gran mayoría o por una poderosa minoría. A su vez, la estructura de una sociedad es un complejo entramado de relaciones sociales que dan nacimiento a relaciones de poder por las cuales los diferentes grupos de esa misma sociedad se encuentran constantemente en una puja por dominar al otro. (Navone, 2005:315)

Incoar la emisión de un concepto cuanto menos correspondiente a la realidad respecto a cómo se ha tratado en el trayecto de la Corte suprema la cuestión racial a la luz del desarrollo de postulados jurídicos de categoría principalmente constitucional, traduce en una referenciación siquiera tangencial o superficial de las relaciones especialmente culturales y políticas de esta variante de discriminación. De tal suerte que se reputó apropiado traer a colación la inmediatamente anterior cita, a efectos de advertir en la discusión temática, lo relevante que se ubica la variedad de figuras del pensamiento del hombre al trascurrir de la humanidad, donde su percepción de lo que recibe como realidad y aspiración de la misma, perspectiva encasillada en la palabra cosmovisión, determina aspectos más allá del fuero interno de su maquinador, esto es, deriva en una afección a los congéneres materializada en mayor o menor medida por los dotes de poder adherido a su ejecutor.

Como se expresó hace poco, el racismo es una subespecie dentro del género de la discriminación, es inexorable, por lo tanto, inquirir que se entiende por dicho termino; en relación a ello, la RAE sostiene: "Acción y efecto de discriminar." Siguiendo la secuencia, sobre discriminar apunta: "1. Seleccionar excluyendo. 2. Dar trato desigual a una persona o colectividad por motivos raciales, religiosos, políticos, de sexo, etc." ${ }^{6}$ De tan lacónica definición resalta un concepto mayor de indefectible inclusión en el contexto del tema señalado, a saber, el de igualdad, entendido este a partir de una comparativa con uno íntimamente afín como:

6 Diccionario de la Lengua Española. Edición del Tricentenario. 
La libertad es la cualidad de un ente, y la igualdad un modo de establecer un determinado tipo de relación entre los entes de una totalidad, a pesar de que la única característica común de estos entes sea el hecho de ser libres. (Bobbio, 1993:56) Cursivas propias.

Concordante a dicha noción de igualdad planteada en una disposición de amalgamiento con el precepto de libertad, se consiente el punto de partida en el distintivo colectivo de la existencia del hombre como coasociado a una integridad eminentemente diversa, que para su subsistencia impetra conferir reconocimientos pares en el individualismo que le asiste a sus integrantes. Pese a ello, tal conciencia social de trato coincidente, la determina en forma ineluctable su análoga conciencia político-cultural, consiguiente esta de los flujos intersubjetivos elevados a acuerdos comunes en las sociedades, siendo estos los que después se estatuyen como principios rectores de los ordenamientos jurídicos incorporándose en las cartas superiores.

Luego entonces, en los anales del derecho constitucional (en especial el anglosajón), han descansado como incuestionables, credos de común reproche en la actualidad, como la misma discriminación racial congénita a la ideología de superioridad de raza. Esto se denota verbigracia en apuntes tales como el de la sentencia Plessy v. Ferguson (1896) dictada por la Corte Suprema de los Estados Unidos con alto contenido segregacionista, no obstante, a darse en un escenario post-esclavista en gracia de la Decimotercera enmienda (1865) a la constitución obrada por el congreso, tal es el siguiente:

[...] Creemos erróneo el argumento del recurrente que parte del supuesto de que la separación obligatoria de las razas implica por si misma que los negros son inferiores. Si ello es así no es porque la ley lo diga o lo de a entender, sino única y exclusivamente porque los negros lo interpretan de esa manera. [...] esta alegación presupone que los prejuicios sociales pueden ser superados promulgando leyes, y también que únicamente se puede asegurar a los negros sus derechos mediante la mezcla forzosa de razas. [...] Si blancos y negros deben convivir en pie de igualdad social, ello debe ser el resultado de afinidades naturales, del mutuo reconocimiento de los méritos y bondades de cada uno de los ciudadanos y del libre albedrio de las personas. (Gonzalez \& Beltran de Felipe, 2006:168) Cursivas propias.

Con la argumentación señalada, la corte certificó tajantemente en términos constitucionales la validez de las actitudes segregacionistas desde el poder público, aun así, el sostén se muestra a todas luces paradójico pues mientras endilga las afectaciones del racismo, en una acción que hoy se tildaría de revictimizante, a las sensaciones personales de los sujetos, aunado al señalamiento de las limitaciones del Estado de intervenir en detrimento de los prejuicios, del mismo aparato estatal dimanan leyes no muy distantes en el tiempo del suscrito fallo, como la Racial Integrity Act (1924) de Virginia con homologas en varios Estados, contraria plenamente a cualquier atisbo de igualdad, la cual a través de un boletín de salud desarrollador de esta, elaborado por el Registrador Estatal de Estadísticas Vitales, acotó:

To succeed, the intermarriage of the white race with mixed stock must be made impossible. But that is not sufficient, public sentiment must be so aroused that intermixture out of wedlock will cease.

The public must be led to look with scorn and contempt upon the man who will degrade himself and do harm to society by such abhorrent deeds. (Government, 1924)

Profundizando el mensaje de repulsión disponía la norma más adelante, siendo estos sus puntos neurales: 
[...] 4. No marriage license shall be granted until the clerk or deputy clerk has reasonable assurance that the statement as to color of both man and woman are correct.

If the is reasonable cause to disbelieve that applicants are of pure white race, when that fact is stared, the clerk or deputy clerk shall withhold the granting of the license until satisfactory proof is produced that both applicants are "white persons" as provided for in this act.

The clerk or deputy clerk shall use the same care to assure himself that both applicants are colored when the fact is claimed.

5. It shall hereafter be unlawful for any white person in this State to marry any save a white person, or a person with no other admixture of blood than white and American Indian [...]. (Government, 1924) ${ }^{7}$

A pesar de los rubores que se pueden presentar al conocer las aristas de este asunto y su otrora legitimidad constitucional, se debe permanecer fijo el criterio analítico de que el poder es quien determina la legalidad y en múltiples escenarios de la historia este no se ha enmarcado en consideraciones racionales o humanistas, como hoy lo gozan v.gr en su condición de universales e inalienables los derechos fundamentales, de tal suerte que inclusive las ciencias no son ajenas a los pensamientos que gobiernan las comunidades, en lo tocante al racismo por citar tan solo un caso, es sumamente llamativo este:

En el siglo XIX y comienzos del XX, había la concepción ampliamente difundida entre científicos e intelectuales de que los seres humanos podían dividirse en un pequeño número de razas más o menos mutuamente excluyentes. Además, según estas doctrinas del llamado racismo científico, cada raza no solo se veía diferente, sino que también tenía una naturaleza esencial diferente que determinaba en gran medida el potencial moral e intelectual de sus integrantes. En pos de este interés, los científicos invirtieron carreras completas midiendo cráneos para definir tales razas y demostrar que la raza blanca o caucásica tenía el cerebro más grande, y por ende el mejor. (Wade, 2011, pág. 210)

Indicando tal circunstancia que cuando una doctrina pulula con beneplácito de sus espectadores, es irrisorio pretender que la ética se imponga cuando esta no le asiste. En simultanea corrobora dicho pasaje que, si bien la esclavitud formalmente había sido abolida, sus repercusiones entendidas como los fenómenos de segregación, racismo e intolerancia sobrevivían materialmente, permeando incluso el alto tribunal americano.

En el derecho constitucional contemporáneo este capítulo parece superado a tal punto que instancias supranacionales se pronuncian al respecto en este sentido: "[...] desde el punto de vista científico y antropológico, el concepto de que los seres humanos pueden dividirse y clasificarse definitivamente en distintas 'razas' carece de fundamento. No hay más que una raza: la raza humana" (Torres Parodi \& Bolis, 2007:406).

Para ultimar esta sección, aparece la incógnita que se agotó previamente, ¿Qué es el principio de supremacía constitucional? esta vez con el agravante de definirlo con observancia a una ideología en días presentes revaluada, cuál es la supremacía de raza, concerniente a ello es propio expresarla como: La sujeción, sin reparos, de la comunidad y el gobierno estatal ante las convenciones político-culturales de sus miembros, esquematizadas en el orden constitucional con

7 La ley en comento fue declara anticonstitucional en sentencia resalutoria del popular caso Loving v. Virginia par parte de la Corte Suprema después de 43 años de vigencia. 
apego pétreo, sin lugar a variantes ideológicas externas o menores, admisibles exclusivamente las que provengan del soberano mismo. El poder judicial es oráculo de la diosa "Ley" por lo que no reviste facultad de cuestionarla por fuera de la moralidad ni la justicia acordada por el supremo.

\subsection{Libertad de Expresión como Máxima Axiológica del Derecho Constitucional Anglosajón}

A estas alturas del escrito, ad portas de alcanzar su finitud, tal vez no se recuerde que al definir igualdad se apeló al pensamiento de Bobbio (1993) para quien esta partía de la noción de libertad que precisaba como "cualidad de un ente", suscribiéndose en la axiomática visión contractualista imperante en la modernidad; empero para dar una respuesta certera es menester acceder a una conceptualización más explícita o aterrizada, por ello se considera valioso relatar las acepciones que para modernos y antiguos tiene la libertad que al respecto hace Benjamin Constant, sobre los primeros comenta es:

El derecho de cada uno a no ser sometido más que a las leyes, a no poder ser ni arrestado, ni detenido, ni muerto ni maltratado de manera alguna a causa de la voluntad arbitraria de uno o varios individuos. Es el derecho de cada uno a expresar su opinión, a escoger su trabajo y a ejercerlo, a disponer de su propiedad, y abusar incluso de ella; a ir y venir sin pedir permiso y $\sin$ rendir cuentas de sus motivos o de sus pasos [...]. (Citado por Carbonell, 2008:36) Cursivas propias.

Mientras tanto, reseña que el significado de libertad para los segundos consiste:

En ejercer de forma colectiva pero directa, diversos aspectos del conjunto de la soberanía, en deliberar, en la plaza pública, sobre la guerra y la paz, en concluir alianzas con los extranjeros, en votar las leyes, en pronunciar sentencias, en examinar las cuentas, los actos, la gestión de los magistrados [...]. (Citado por Carbonell, 2008:37)

Sé deduce así que la concepción actual en la que se establece el ideario de libertad, subsumiéndose desde luego, la libertad de expresión en está, es en una posición de acreencia legal u ostentación de derecho reconocida a toda la ciudadanía para su desenvolvimiento en la variedad de estamentos sociales. Se relegó la perspectiva de libertad sustentada en participación política a las formas democráticas de organización y sus mecanismos de intervención.

Desde las providencias de la Corte suprema de los EE. UU sometidas a estudio alusivas a la materia, esto es, West Virginia State Board Of Education v. Barnette, así como Texas v. Johnson, se pone de relieve la valía significativa concedida y tutelada en el sistema norteamericano, uno de los apartes más trascendentales que servirían como faro para dilucidar futuros debates litigiosos que incumbieran el derecho a la libre expresión, fue este del primer fallo citado:

Si hay alguna estrella inamovible en nuestra constelación constitucional es que ninguna autoridad pública, tenga la jerarquía que tenga, puede prescribir lo que sea ortodoxo en política, religión, nacionalismo u otros posibles ámbitos de la opinión de los ciudadanos, ni obligarles a manifestar su fe o creencia en dicha ortodoxia, ya sea de palabra o con gestos. No se nos alcanza ninguna circunstancia que pueda ser considerada una excepción a esta regla. (Gonzalez \& Beltran de Felipe, 2006:273)

Se puede decir entonces que la magnitud endilgada de la libertad de expresión es uno de los pilares sobre lo que descansa el Estado y le posibilita gozar de legitimidad; a pesar de ello, le resiste al ordenamiento jurídico anglosajón, como a casi todos que propugnen por una estructura 
democrática, lo que (Sunstein, 2006) denomina la tenencia de acuerdos carentes de una teoría completa en derecho constitucional, según este autor: "Ordenamientos constitucionales que funcionan bien tratan de resolver problemas a través de acuerdos carentes de una teoría completa".

Estos acuerdos incluyen a veces abstracciones aceptadas como tales, en medio de desacuerdos severos sobre casos particulares; sin embargo, ello no puede servir de empresa a quienes ante tal situación pregonan la insostenibilidad del establecimiento constitucional puesto que los absolutos ciertamente no existen y en garantía de lo que históricamente se ha construido como derecho debe prevalecer lo favorable del eclecticismo para subsanar incompatibilidades y so pena de ser riesgoso, servirse de lo utilitarista en cuanto a fines ante lo inalcanzable de llenar todas las bases.

Bajo este panorama se forma el principio de supremacía constitucional desde la libertad de expresión como: materia prima y producto de las soberanas comunicaciones entre homólogos de una nación que consienten en un sistema de normas dirigido por sus máximas orientadoras signadas en una constitución, destacado por ser respetuoso esencialmente de su factor de composición, esto es, la libertad de expresión en sus variadas manifestaciones.

\section{4. ¿Cómo la Corte Suprema de los Estados Unidos con Fundamento en la Supremacía Constitucional ha Implementado Políticas Públicas?}

En este terreno se torna inoportuno entrar a discutir lo que en diversas y abundantes definiciones de políticas públicas, se puede resumir grosso modo como la exteriorización de la voluntad de la administración frente a situaciones primordiales de sus integrantes; el quid del 114 asunto aquí radica en determinar si está habilitado o no el Tribunal Supremo de EE.UU, de paso cualquier alta corte legitimada por su respectiva constitución, para ejercitar dicho accionar de la institucionalidad que recae por excelencia en la rama ejecutiva del poder público.

Tal posibilidad es reseñada bajo la denominación de activismo judicial, la cual, si contiene virtud para ocuparle ciertas lacónicas consideraciones, ello por ser axiomático las confusiones que genera su empleo dentro de la doctrina y la administración de justicia misma, con otros aparentemente homólogos como es el caso del vocablo judicialización. Sobre el particular se indica que: "A judicialização e o ativismo judicial são primos. Vêm, portanto, da mesma família, freqüentam os mesmos lugares, mas não têm as mesmas origens. Não são gerados, a rigor, pelas mesmas causas imediatas." (Barroso, 2009:21). Se parte entonces de que existe una relación intrinseca admitida entre dichas nociones, luego ¿Qué las distingue entre si? En una basica acción interpretativa de deducción, se advierte que si se emplea el epiteto activismo, se está haciendo una analogía valorativa interna frente a un estado previo de quietud o reposo (cuando menos, de un actuar mesurado), así se deviene de consultar la definición que de este termino confiere la RAE: "Activismo: Tendencia a comportarse de un modo extremedamente dinámico." ${ }^{8}$ Anotación que explica que con esta calificación se le arroga a la función jurisdiccional un rol de gran trascendencia en las esferas públicas por su quehacer proteccionista de las garantías individuales y la tutela a ultranza de la consigna de supremacía constitucional; a tales luces se colige que la postura activista de los poderes judiciales es consecuencia inmediata de la judicialización constitucional de los sistemas normativos así como de los estados mismos, concebida esta de la siguiente forma:

[...] Es resultado, de una manera general, de un proceso histórico típico del constitucionalismo democrático que tiene por base múltiples factores, tales como la centralidad de la Constitución y

8 Diccionario de la Lengua Española. Edición del Tricentenario. 
su fuerza normativa, asociadas a aspectos como el carácter principista, la supremacía y la dimensión objetiva de los derechos fundamentales [...] (Hennig Leal, 2012:434) Cursivas propias.

Reflexión de la que sobresale de a bulto que este proceso no es súbito en el orden existente de los ordenamientos jurídicos gobernados por el paradigma neoconstitucionalista, de hecho ni siquiera es exclusivo del escenario actual, más por el contrario, la judicialización es la manifestación de un fenomeno recidivante tal cual lo es la sintetización de los factores ostentores de consuno o auspicio por parte de las expresiones de poder vigentes en las comunidades, que para el caso en particular de la modernidad, tienen como ejes, la jerarquización común de los sistemas normativos a partir de una célula irradiadora de los mismos desde la cual deben desarrollarse (Constitución o Ley Fundamental), y la inserción (sin condicionamientos para su efectividad) de los derechos universalmente reconocidos en la misma adheridos a unos instrumentos para su materialización.

Una noción más tecnica, a la vez más explícita de lo que significa está expresión al interior de la cultura jurídica, a la cual el padre de la teoría pura del derecho arriba mencionado catalogaría sin acoquinamiento alguno como una flagrante espoliación del oficio del legislador positivo, es esta:

[...] tipo de relación que establecen los jueces con las personas y con los otros órganos del Estado, a partir de una decisión caracterizada por delimitar los alcances de las normas jurídicas, estableciendo significados que no surgen de la literalidad de esas normas, y que pueden incluir la definición de políticas públicas o la invalidación de las decisiones o de las políticas públicas diseñadas por otros órganos estatales. (Feoli, 2015:132)

De esto resulta que el activismo judicial concentra un trato de eficacia de las cargas subjetivas de las personas, dirigido por los encomendados a la labor de administrar justicia, en cuyo propósito la regencia de tales prebendas con raigambre constitucional, les concede potestad tanto para crear planes de indole ejecutivos en procura de su vigor, como para anular los dimanados por otras instancias estatales cuando se juzgan antagónicos a la constitución. Operando de tal modo, el principio de supremacía constitucional como precepto de factibilidad de este ensanchamiento jurisdiccional.

Se puede declarar a la sazón consumada, o en en proceso de realización para no estribar en irrealismos, la transmutación de la ciencia jurídica advertida recientemente cuando con ocasión a los retos del derecho ante los procesos de evolución y apertura ejecutándose en el escenario mundial se señaló:

[...] el Derecho tendrá que abordar desde su naturaleza cognitiva problemas que van más allá de sus límites, lo que significa que tendrá que sufrir una metamorfosis o una evolución darwiniana de su especie para comprender metajurídicamente las nuevas realidades sociales, como el matrimonio igualitario, la adopción de niños y niñas por parejas del mismo sexo, las despenalización del aborto en el mundo, la legalización de las drogas, el reconocimiento de la eutanasia con fundamento en el libre desarrollo de la personalidad y de la dignidad humana. (Rodríguez Serpa, 2013:11)

Habiendo surtido medianamente dicha precisión conceptual sobre tales terminos, profusos en el argot jurídico contemporáneo, siendo por demás requerida, se retoma el propósito de este apartado con cierta lucidez garante de una contestación más certera al cuestionamiento instaurado. 
Así las cosas, para determinar entonces si el poder judicial puede invadir las esferas de competencia del ejecutivo, es vinculante examinar el nivel de respuesta otorgado por este a las situaciones problemáticas que luego terminan siendo objeto de atención por el poder judicial, desde esa óptica, sostiene Becker "Así, la importancia política actual de las intervenciones judiciales se derivaría, más bien, del creciente involucramiento de la jurisdicción en los conflictos sociales o en temas políticos y sociales no resueltos (o mal afrontados) en su debido nivel político general" (Citado por Henao Perez, 2013:72)

Es corolario aseverar que la injerencia del poder judicial en la atención de asuntos de resorte ejecutivo, se convalida en virtud de la inacción del último en cuestiones de impostergable satisfacción como bien lo son el cubrimiento de los derechos fundamentales generalmente comportando tal pasividad un eventual o inminente detrimento frente a estos.

Toda esta disputa de competencias se inicia precisamente en ocasión a uno de los fallos del tribunal supremo estadounidense relativo a la proscripción de la segregación por motivos de raza, el citado caso Brown v. Board of Education of Topeka, tal como apunta Gonzalez \& Beltran de Felipe (2006:292-293) este veredicto contó con solida renuencia a su acatamiento por parte de algunos Estados confederados, condición esta de federalismo que daba mayor complejidad, por lo que la corporación, soportada en una conducta activista se vio avocada en procesos posteriores disponer planes de acción concretos en aras de dotar de cumplimiento sus providencias y afianzar la seguridad jurídica (Swann v. Charlotte-Mecklenburg Board of Education 1971).

En ese entendido, tiene asidero asentir la intrusión del poder judicial en el manejo de la agenda de políticas públicas con apoyo en el principio de supremacía constitucional dado el rigor de la constitución en el sistema, esto de manera excepcional en los supuestos de hecho en los cuales el estamento institucional designado se denote inoperante en atender los requerimientos de diversa naturaleza que derivan constantemente del conglomerado social, frente a los cuales el derecho como herramienta de regulación y cohesión no puede advertirse estático, en cambio, debe hacer gala de su cada vez más pregonada naturaleza autopoiética ${ }^{9}$.

\section{CONCLUSIONES}

Las motivaciones que impulsaron la disertación de este tópico de la dogmática contemporánea fueron variadas, entre ellas vale mencionar la propia actualidad del asunto macro dentro de la doctrina del derecho público, a saber: el neoconstitucionalismo; de mayor incidencia que la anterior lo fue las extendidas consecuencias de la actividad jurisdiccional en el funcionamiento del aparato estatal, la mutación de los criterios de interpretación de la ley a fuentes formales afianzadas del derecho, y como determinante de dicha indagación, de la cual lógicamente deviene este artículo, se instala el uso del principio de supremacía constitucional como argumento sustancial en las escasas discusiones que se suscitaron referente a la adopción en Colombia de esta tendencia como paradigma normativo o la permanencia del tradicional formalismo jurídico ${ }^{10}$, hecho que acarreó auscultar acerca del contenido del mismo así como de su proceso formativo, ubicando el campo de estudio en el derecho anglosajón, más precisamente, en la jurisprudencia de su máximo tribunal de justicia.

A través de un extenso ejercicio de consulta en la literatura científica tratante de la materia, se pudieron establecer como preponderantes en los veredictos de la Corte Suprema de los EE.UU las doctrinas a la luz de las cuales se pretendió conceptualizar el principio de supremacía constitucional, esto es: el principio rector en sí mismo considerado, la libertad de expresión y la

9 Concepto extrapolada de las Ciencias Naturales por Niklas Luhmann, desarrollado entre otras por, Marcelo Neves y Fernando Galindo. I0 Se alude al intercambio de misivas entre el Profesar Diego E. López Medina y el Exmagistrada F. Javier Tamaya Jaramillo. 
hegemonía de raza; guardando entre sí cada tentativa de definición, notorias distinciones que se evidencian en el cuerpo de los capitulos.

No obstante, se refleja como punto de convergencia entre estos, si es que puede considerarse como un común denominador, su carácter dúctil en cuanto a esencia y composición pues este, el principio de soberanía de los textos superiores y actualmente el de sus interpretaciones, ha correspondido a las especialísimas condiciones en que se ha gestado, marcando distancia de un rol inmutable, conservando únicamente su institución constitucional.

Se pudo abordar desde un enfoque con fuerte certidumbre, pues se distinguió entre fenómenos de habitual confusión (Judicialización - Activismo Judicial), si la corporación judicial sub examine estaba cualificada para la creación y puesta en marcha de políticas públicas valiéndose para tal suerte de la legitimidad transferida por el principio de supremacía constitucional en dicho actuar; obteniendo como respuesta a tal interrogante, la aceptación de tales ejercicios en cuanto refieran a la protección y eficacia de las garantías individuales constitucionalmente reconocidas en el sistema jurídico, siendo entonces admisible estos procederes por parte del ramo jurisdiccional del Estado en el exclusivo evento de la incuria insistente de su homólogo estructural del poder público, ramo legislativo.

Por último, se espera que este humilde apunte de reflexiones con sus indiscutibles limitantes de cualquier naturaleza imaginable, favorezca a continuar el estudio crítico de la vertiente neoconstitucional gobernante en cantidad de sistemas legales en la actualidad, en aras de su consolidación, escrutinio en cada una de sus aristas o su revaluación respecto a su vigencia y conveniencia pues esta se descubre como un compuesto de heterogeneidad que niega su formulación como una teoría jurídica uniforme, en paradoja palmaria con una de sus premisas básicas cual es la integridad de los ordenamientos, situación que le hace merecedora de justos reparos y exhortan las voces de rescate de la cada vez más oxidada corriente ius positivista ${ }^{11}$. Concurren, además, otras perspectivas que deben ser exploradas detenidamente sobre el auténtico significado del neoconstitucionalismo pues hay quienes plantean incluso su inexistencia mientras que invocan que lo suscitado es la "positivización del iusnaturalismo"12, mientras que paralelamente otros se dedican a acusar las contrariedades de sus procedimientos como es el caso de la revisión de constitucionalidad de los proyectos de reformas a la carta ${ }^{13}$, pues sostienen ilógico pretender la adecuación a la constitución de una acción política-jurídica cuyo fin explicito es modificar a la misma; estudios estos, de los cuales se ambiciona ser un referente inicial.

\section{REFERENCIAS}

II Férrea apasitar de este modela y su expansión en las culturas jurídicas contemporáneas ha sida el Profesar Juan Antania García Amada can sólidos análisis argumentales al respecto.

12 Pastura sastenida par el Magistrado emérita del Tribunal Constitucional Español, Dr. Manuel Aragán Reyes en: Reyes, M. A. (2013). Das problemas falsas y uno verdadero: "neaconstitucionalismo", "garantismo" y aplicación judicial de la Canstitución. Cuestiones constitucionales, 29, 3-25.

13 Menéndez, I. V. (20I2). El control de constitucionalidad de las reformas constitucionales. illn axímaran constitucional? Comentario al ATC 9/2012. Teoría y Realidad Constitucional, (30), 483. 


\section{Aldunate, E. (15 de Junio de 2009). Neoconstitucionalismo. Anuario de Derecho Público UDP, p.} 7.

Barroso, L. (2009). Judicialização, Ativismo Judicial E Legitimidade Democrática. Anuario Iberoamericano de Justicia Constitucional(13), 17-32.

Bobbio, N. (1993). Igualdad y libertad. Barcelona: Paidós.

Carbonell, M. (2008). Benjamin Constant: Libertad y participación política. Metapolítica, 36-40. Recuperado de EbscoHost.

Comanducci, P., Ahumada, M., \& Gonzalez, D. (2009). Positivismo jurídico y neoconstitucionalismo. Madrid: Fundación Coloquio Jurídico Europeo.

Feoli, M. (2015). Las cortes super poderosas: ¿activismo o visibilidad?. Pensamiento Juridico, 127162. Recuperado de ProQuest.

Gonzalez, J., \& Beltran de Felipe, M. (2006). Las sentencias básicas del tribunal supremo de los Estados Unidos. Madrid, España: Boletin Oficial del Estado.

Government, L. (1924). The New Virginia Law To Preserve Racial Integrity. Virginia Health Bulletin, 1-4.

Hamilton, A., Madison, J., \& Jay, J. (2015). El Federalista. Madrid, España: Akal S,A.

Henao Perez, J. C. (2013). El juez constitucional: un actor de las politicas pùblicas. Revista de Economia Institucional, 67-102. Recuperado de EbscoHost.

Hennig Leal, M. (2012). La Jurisdicción Constitucional entre Judicialización y Activismo Judicial: ¿Existe realmente "Un Activismo" o "El" Activismo? Estudios Constitucionales, 10(2), 429454.

Navone, K. (2005). Lecciones y ensayos. Buenos Aires: LexisNexis.

Rodríguez Serpa, F. (Enero-Junio de 2013). ¿Hacia dónde va epistemológicamente el derecho? Justicia, 8-17.

Rodríguez Serpa, F., Herrera Tapias, B. \& De la Torre Soto, G. (2018). Estado Social de Derecho. Una comprensión metajurídica. En: panorama jurídico y sociojuridico de los derechos humanos, sociales y ambientales. tomo II. Barranquilla, Colombia: Universidad Simón Bolívar.

Sanchís, L. P. (2009). Justicia Constitucional \& Derechos Fundamentales. (2a Edición ed.). Madrid, España: Editorial Trotta.

Silva Irarrázaval, L. A. (2012). ¿Es el tribunal constitucional el supremo interprete de la constitución? Revista de Derecho de la Pontificia Universidad Católica de Valparaíso, $573-$ 616. Recuperado de ProQuest. 
Sunstein, C. (2006). Acuerdos carente de una teoría completa en derecho constitucional. Precedente. Revista Jurídica, 31-49.

Torres Parodi, C., \& Bolis, M. (2007). Evolución del concepto etnia/raza y su impacto en la formulación de políticas para la equidad. Panam Salud Pública, 405-416.

Trovao Do Rosario, P. (2015). Tribunal Constitucional ¿Un legislador negativo o positivo? Revista de Derecho UNED(16), 713-740.

Velásquez, A. M. (16 de Junio de 1998). El caso Bonham. Supremacía Constitucional. Revista de Derecho, 1-5. Recuperado de EbscoHost.

Wade, P. (Enero-Junio de 2011). Raza y naturaleza humana. Tabula Rasa, 205-226. 
Aproximación a una Conceptualización de la Supremacía Constitucional a partir de la Jurisprudencia de la Corte Suprema de los EE. UU

Héctor Mario Sulbaran Álvarez

Estudiante de X Semestre de la Facultad de Derecho de la Universidad de la Costa CUC. Miembro del grupo de Investigación: Derecho, Política y Sociedad de la misma casa de estudios. Orcid.org/0000-0002-7171-0355 